\title{
Physical activity and endometrial cancer in a population-based case-control study
}

\author{
Hannah Arem, Melinda L. Irwin, Yang Zhou, Lingeng Lu, Harvey Risch, and Herbert Yu \\ Department of Chronic Disease Epidemiology, Yale School of Public Health, 60 College St, Room \\ 428, PO Box 208034, New Haven, CT 06520-8034, USA
}

Melinda L. Irwin: melinda.irwin@yale.edu

\begin{abstract}
Introduction-Published studies of physical activity, BMI, and endometrial cancer risk show conflicting results and many do not report on reliability or validity of physical activity questionnaires.
\end{abstract}

Methods-We collected physical activity data on 667 incident cases of endometrial cancer and 662 age-matched controls. Interview-administered questionnaires, collecting demographic and lifestyle information, including a validated questionnaire for physical activity. We performed unconditional logistic regression to examine the relationship between moderate- to vigorousintensity sports/recreational physical activity (MV PA), sit time, and endometrial cancer risk.

Results-Compared to women reporting 0 metabolic equivalent (MET) hours per week of MV PA, those who reported 7.5 MET h/wk or more had a 34\% lower endometrial cancer risk (odds ratio $(\mathrm{OR})=0.66,95 \% \mathrm{CI} 0.50-0.87)$ after adjusting for risk factors including BMI. Those women sitting more than $8 \mathrm{~h}$ per day had a $52 \%$ increased odds (95\% CI 1.07-2.16) of endometrial cancer compared to those sitting less than $4 \mathrm{~h}$ per day. We created a composite measure of physical activity and BMI and found that women with a BMI $<25$ and activity levels $\geq 7.5 \mathrm{MET}$ h/wk had a $73 \%$ lower endometrial cancer risk $(\mathrm{OR}=0.27,95 \% \mathrm{CI} 0.18-0.39)$ compared with the reference group of overweight (BMI $\geq 25$ ) and sedentary (MET h/wk $=0$ ).

Conclusion-Our data support an inverse, independent association between physical activity and endometrial cancer risk after adjusting for BMI and other risk factors.

\section{Keywords}

Physical activity; Endometrial cancer; BMI

\section{Introduction}

In the United States in 2009, 42,000 women were diagnosed with endometrial (uterine corpus) cancer, making it the fourth most common incident cancer among women [1,2]. According to Surveillance Epidemiology and End Results (SEER) data, five-year survival rates are $95.5 \%$ for localized cancers (70\% of those diagnosed), $67.5 \%$ for regional cancers, and $17.1 \%$ for cancers that have metastasized. Research suggests that hormonal and lifestyle factors such as parity, oral contraception, body mass index (BMI), physical activity, and diet may explain up to $80 \%$ of the risk of this disease [3].

(c) Springer Science+Business Media B.V. 2010

Correspondence to: Melinda L. Irwin, melinda . irwin@yale. edu. 
Unopposed estrogens are thought to underlie the relation between BMI, physical activity, and endometrial cancer [4]. Suggested biological mechanisms for this relationship include changes in percent body fat, sex hormones, insulin, insulin-like growth factor-1, leptin, and adiponectin levels [5]. The 2007 World Cancer Research Fund and American Institute for Cancer Research (WCRF/AICR) found "probable" evidence of a link between physical activity and endometrial cancer risk [6]. A 2007 systematic review of 20 published studies on physical activity and endometrial cancer risk showed that eight of ten studies deemed to be high quality observed a risk reduction of $15-30 \%$ comparing the most active to the least active women [7]. Of the case-control studies with less favorable quality scores, results varied from twofold increased risk to twofold decreased risk, and interactions with BMI and menopausal status were not consistent. Another review of physical activity and endometrial cancer risk published the same year based on 18 overlapping studies showed a "convincing or possible protective effect," averaging a risk reduction of 30\% [8]. Of the included studies, validity and reliability of physical activity measures were only available for seven studies [9-15], and measurement methods were not well described. A recent meta-analysis of 14 prospective cohort studies on physical activity and endometrial cancer risk suggests that the recently published evidence strengthens the "probable" link to a "convincing causal relationship" as defined by the WCRF/AICR report [16]. Although the strength of the evidence is growing, null and contradictory results raise questions about the association between intensity and timing of physical activity with risk of endometrial cancer and the validity of physical activity measurements. Published case-control and cohort studies utilize a variety of physical activity measurements, and only some [10,13,15,17-22] reported on intensity of activity and risk. Sitting time is also emerging in the literature as a possible independent risk factor for endometrial cancer [15,17,20,23,24].

Because of inconsistent findings from previous studies, we evaluated the independent associations between physical activity, BMI, and the combination of physical activity and $\mathrm{BMI}$ on risk of endometrial cancer. We also investigated the association between sitting time and physical activity, given recent publications supporting an association with endometrial cancer risk. We hypothesized that higher physical activity, low sitting time, and lower BMI would independently reduce risk and that the combination of high physical activity and low BMI, compared with low physical activity and high BMI, would be associated with lower endometrial cancer risk.

\section{Methods}

\section{Study design}

This population-based case-control study recruited English-speaking, Connecticut residents diagnosed with primary endometrial cancer between October 2004 and September 2008. Over the period of eligibility, study staff of the Rapid Case Ascertainment (RCA), a shared resource of the Yale Cancer Center, regularly visited all Connecticut general hospitals to obtain case eligibility and identifying information. Of 1,663 potentially eligible case patients, we sought physician consent for 1,270 and obtained consent for 1,242 (97.8\%). Physician consent was not sought for the remaining potentially eligible participants because planned sample size was attained. After receipt of physician consent, research staff were able to contact 1,216 patients and enrolled 668 (54.9\%) of those approached. Among the 1,216 patients approached, 317 (26\%) chose not to participate, $19(1.6 \%)$ had died, 13 (1.1\%) were too ill, $44(3.6 \%)$ could not be located, 68 (5.6\%) could not be reached by telephone, and 87 (7.3\%) were ineligible (residence outside of Connecticut or in nursing facility $(n=18)$, mental impairment $(n=17)$, language barrier $(n=27))$, and ineligible diagnosis $(n=25)$ ). Population-based controls were identified using random-digit dialing (RDD) and were frequency matched on age (35-51, 52-59, 60-64, 65-69, 70-74, and 7579 years). Among 8,168 residential telephone numbers in Connecticut identified through 
RDD, 1,995 yielded women in the desired age range, and 1,447 (72.5\%) agreed to further contact for participation. We sequentially contacted 1,248 subjects before the end of the study, 111 of whom were ineligible due to residence, mental impairment, language barrier, cancer diagnosis, and ineligible medical conditions. Another 92 were disqualified due to illnesses, heath, relocation, and no response. Of the 1,045 remaining women who had not undergone hysterectomy, 371 refused to participate and 674 completed the interview, leaving a response rate of $64.5 \%$.

Research staff travelled to participant homes to undertake in-person interviews. After completion of signed informed consent, study staff administered structured questionnaires on ethnic and demographic factors, environmental exposures, and lifestyle factors and then measured height, waist, hips, and arm span. Information on weight was gathered through self-report, and BMI was therefore calculated based on self-reported measures. The study was approved by the Institutional Review Boards of Yale University, Connecticut State Department of Public Health, and the 28 participating Connecticut hospitals.

Physical activity levels were determined by administration of Kriska's Modifiable Activity Questionnaire (MAQ), which inquires about 29 types of physical activities [25]. This questionnaire captures moderate- to vigorous-intensity sports/recreational physical activity (MV PA), the intensity level recommended in the 2008 Health and Human Services Physical Activity Guidelines and also by the American College of Sports Medicine and American Heart Association to improve and maintain health [26,27]. The interviewer-administered MAQ demonstrates both high validity and reliability $(r=0.73$ with double labeled water and $r=0.92$ for three-week retest) [25]. Metabolic equivalents (MET) were used to measure physical activities according to the Compendium of Physical Activities (28). One MET, defined as the ratio of work metabolic rate to a standard resting metabolic rate of 1.0 (4.184 $\mathrm{kJ} \mathrm{kg}^{-1} \mathrm{~h}^{-1}$ ), is considered a resting metabolic rate achieved during quiet sitting. MET levels were calculated as hours per week from self-report of various forms of activity (average times per week, average minutes per time, and number of months per year) performed in the two to five years before interview. Activities were characterized as light ( $<3$ MET), moderate (3-6 MET), or vigorous ( $>6$ MET) [28].

\section{Statistical analysis}

Data were first examined to exclude ineligible controls using a priori criteria of women who had a hysterectomy or were outside the specified age range. We then performed descriptive analyses using the $\mathrm{t}$-distribution for continuous variables and $\chi^{2}$ distribution for categorical variables and assessed all variables of interest (Table 1) for confounding. Using unconditional logistic regression, we examined the significance of individual variables with respect to risk of endometrial cancer. Final statistical models were built using backwards selection. We retained variables significant at the two-sided $p=0.05$ level or which caused a $>10 \%$ change in odds ratio estimates of variables of interest. Age and race categories were included in all models. MV PA MET h/wk was explored using a priori categories of $0,>0$ to $<3,3$ to $<7.5$, and $7.5+\mathrm{MET} \mathrm{h} / \mathrm{wk}$, as $7.5 \mathrm{MET} \mathrm{h} / \mathrm{wk}$ is equivalent to $150 \mathrm{~min} / \mathrm{wk}$ of moderate-intensity physical activity, the current recommended minimum for physical activity in the United States [26]. We also created a six-category composite measure of BMI and physical activity to examine joint associations. Categories were normal weight (BMI $<25)$ and physically active (MV PA MET h/wk $\geq 7.5$ ), normal weight and low activity (0 $<$ MET h/wk $<7.5$ ), normal weight and sedentary (MET h/wk $=0$ ), overweight (BMI $\geq 25$ ) and active, overweight and low activity, and overweight and sedentary. To explore whether an interaction existed, we created a new term combining continuous BMI and continuous MV PA. We also examined physical activity levels both in the period two to five years before interview and at ages 30-40 years to clarify the importance of MV PA timing. Separate analyses were performed by menopausal status as reported at time of interview 
(dichotomous categorization as having stopped menstrual periods for at least 12 months) to assess menopause-specific associations. We also analyzed sitting time for an association with endometrial cancer. Time seated watching multimedia or sitting at work was ascertained separately for weekends and weekdays. The final statistical models included adjustment for age at interview (continuous), race (white or other), number of live births, menopausal status (yes/no), oral contraceptive use (ever/never), smoking category (current, former, never) and hypertension (yes/no). Trend analyses were performed using scored MV PA and sit time categories of 1-4.

\section{Results}

Of the 674 control subjects, six were excluded due to hysterectomy and three were excluded due to age greater than 81 years, leaving a control sample size of 665. Physical activity and sitting data were missing for one case and three controls, leaving a final sample size of $n=$ 667 cases and $n=662$ controls. Differences between cases and controls are shown in Table 1 (demographic and lifestyle factors) and Table 2 (physical activity measures). On average, cases had a higher BMI $\left(p=1.78 \times 10^{-38}\right)$, higher rates of diagnosed hypertension $(p=1.43$ $\left.\times 10^{-10}\right)$, diabetes $\left(p=2.70 \times 10^{-5}\right)$, and a greater percentage who had relatives with endometrial cancer $(p=0.024)$. A lower percentage of cases were white $(p=0.0,096)$ and had completed greater than 12 years of education compared with controls $(p=0.0,003)$. Cases were less likely to have smoked $(p=0.0,187)$, drank alcohol $\left(p=3.79 \times 10^{-7}\right)$, or reported menopausal hormone use $(p=0.0,056)$, had fewer live births $\left(p=4.42 \times 10^{-6}\right)$, and lower age at first pregnancy $\left(p=3.13 \times 10^{-5}\right)$, and reported less MV PA in the past two to five years $\left(p=3.19 \times 10^{-9}\right)$ compared with controls.

As presented in Table 3, after adjusting for age and using a priori MET $\mathrm{h} / \mathrm{wk}$ categories of 0 , $>0$ to $>3,3$ to $<7.5,7.5+\mathrm{MET} \mathrm{h} / \mathrm{wk}$, women who participated in more than 7.5 MET h/wk of MV PA had a 54\% reduction (95\% CI 0.36-0.60) in risk of endometrial cancer compared with those who were least active. Adding BMI to the model showed an attenuated odds ratio (OR) of 0.68 (95\% CI 0.52-0.89). After adjustment for other predictors and confounders, the odds ratio for endometrial cancer at the highest level of physical activity compared with the lowest was $\mathrm{OR}=0.66$ (95\% CI $0.50-0.87)$.

Limiting analysis to postmenopausal women strengthened the protective association of physical activity on endometrial cancer comparing the least and most active groups $(\mathrm{OR}=$ 0.61, 95\% CI 0.45-0.83). Removal of sit time from the MV PA model did not change the odds ratio of the highest MV PA category by greater than 10\%, suggesting that it is not a confounder. Thus, sit time was not included in the model for MV PA and endometrial cancer risk but was examined for an independent association with the outcome of endometrial cancer (Table 4). Sit time was statistically significant when comparing the most sedentary to the least sedentary women and adjusting for variables included in the full model $(\mathrm{OR}=1.52$, 95\% CI 1.07-2.16). Our study did not show an association between MV PA at age 30s and risk of developing endometrial cancer (data not shown).

Creation of an interaction term between BMI and MV PA also did not demonstrate a statistically significant term. While an interaction term was not used in the model, Fig. 1 demonstrates multiplicative odds ratios using a composite measure to examine the combined influence of physical activity and weight. We found that those with a BMI $<25$ and reported $\mathrm{MET} \mathrm{h} / \mathrm{wk} \geq 7.5 \mathrm{had}$ an odds ratio of 0.27 (95\% CI 0.18-0.39) for endometrial cancer compared with those who were overweight $(B M I \geq 25)$ and sedentary $($ MET h/wk $=0$ ) (Fig. 1). Comparing women who were overweight and active to ones who were overweight and sedentary, we observed an odds ratio of 0.48 (95\% CI 0.38-0.88). This figure highlights the different magnitudes of decreased risk among different BMI categories. 


\section{Discussion}

Our findings show that MV PA, two to five years before diagnosis, is significantly associated with a lower risk of endometrial cancer even after adjustment for BMI and other endometrial cancer risk factors. Although there was a stronger association among postmenopausal women, there were too few women in the premenopausal group to make conclusions about stratified associations. Risk reduction when comparing women who perform MV PA to sedentary women persisted across both normal weight and overweight women, suggesting that benefit from MV PA is not limited to a single weight group. Even though there was attenuation of the odds ratio with inclusion of BMI (Table 3), the association between physical activity and endometrial cancer persisted in various models, both without and with adjustment for other predictors and confounders. This persistent association suggests that the benefit of PA on risk of endometrial cancer is not completely mediated through effects on BMI.

These findings are consistent with previous publications and meta-analyses linking physical activity to endometrial cancer risk reductions between 20 and 50\%. The published null results may be explained in part by low case numbers $(n<50)[9,29]$. Another null study was based in a highly active Chinese population where few participants were sedentary until late in life (30). An interaction between MV PA and BMI was not observed, and only limited studies have previously examined the combined association of MV PA and BMI on risk or odds of endometrial cancer [15,17,20,31]. This study also confirms previous findings showing an association between sit time and endometrial cancer [17,20,23].

Mechanisms thought to explain the relationship between endometrial cancer risk and physical activity largely relate to sex hormone and insulin pathways. Physical activity reduces serum levels of estradiol and increases levels of its binding protein, sex hormonebinding globulin (SHBG) [5]. Increased physical activity levels are related to lower insulin levels [32] and improved insulin sensitivity [33], which lowers exposure to hormones and growth factors available in the blood. Increased physical activity has also been shown to improve free radical defenses by upregulating free scavenger enzymes and antioxidant levels [34]. Exercise is also linked with an increase in antitumor immune defenses and improvements in antioxidant defense systems, increasing the number and activity of macrophages, lymphokine-activated killer cells and regulating cytokines [35]. A 2002 paper on etiological evidence and biological mechanisms relating physical activity to cancer outcomes suggested a decrease in percent body fat as the major biological factor [36].

One recently published study found a significant association between daily sitting time and increased risk for cardiovascular disease and overall mortality [37]. Other studies have linked television viewing to higher risks of obesity [38], metabolic syndrome [39,40], and type II diabetes (38), independent of physical activity levels. A previous study looking at occupational sit time in relation to risk of endometrial cancer showed null results overall and an odds ratio of 0.64 (95\% CI 0.42-0.99) comparing quartiles of postmenopausal women who sit more to those who sit less [15]. However, job codes were used to estimate sit time in the null study and may not have been accurate for this purpose. Another recently published study found a $42 \%$ increase in endometrial cancer risk (95\% CI (1.06-1.90), $p$ trend $=$ 0.009) among those with the highest levels of lifetime occupational sit time [24].

Limitations of this study include the possibility that the interviewer-administered questionnaires were subject to differential recall by case or control status. This could increase the magnitude of the observed difference in risk between groups. Weight data were collected by self-report and may be subject to underreporting. Subjects also might overreport physical activity levels due to social desirability bias. Also, the MAQ was validated 
for activity within the past year and not two to five years prior and thus may be slightly less valid. However, only MV PA was included in the analysis, and this may be easier to recall then low-intensity activities such as household work. Furthermore, the magnitudes of association for MV PA were similar to those observed in other case-control and cohort studies, strengthening the body of evidence surrounding the relationship between physical activity and endometrial cancer. Response rates were low as only $54.9 \%$ of cases and $64.5 \%$ of controls approached were enrolled in the study. Exclusion of very ill women could result in selection bias. Only $1.1 \%$ of the women refusing to participate did so because they were too ill, although it is possible that physicians may not have given consent to contact for patients in poor health. These biases may overestimate the association between physical activity and risk of endometrial cancer.

Strengths of our study include the use of validated and detailed physical activity measurements. Our questionnaire measured 29 different types of physical activities and was used to isolate those activities that were moderate to vigorous intensity. Moderate to vigorous intensity activity is supported in the literature as it is believed to reduce risk of some types of cancer [41]. Also, timing of physical activity was explored, and measurements from two to five years in the past were used in attempt to lessen the possibility of overt disease or preclinical symptoms among cases that could affect activity levels. Physical activity levels in the years preceding diagnosis would affect unopposed estrogen levels and could be an etiologically relevant time period for onset of endometrial cancer, although the timing of exposure to protective factors for endometrial cancer is still under debate. Our data showing a null relationship between activities at ages 30-39 may be due to poor recall of activity levels or could imply that earlier exercise is not associated with endometrial cancer risk. Household and occupational activity has also been linked to lower endometrial cancer risk, but measurement estimates of expenditure are imprecise [15,42]. Our study was population based, making results more generalizable than hospital or other population-specific groups.

Endometrial cancer is currently the fourth most common cancer among women [43], and as obesity rates in the United States and worldwide continue to rise, endometrial cancer incidence will likely increase. A study based in the American Cancer Society Cancer Prevention cohort of over 900,000 individuals showed that among endometrial cancer patients, those with a BMI of above 25 had an increased risk of mortality compared with those who were normal weight [44]. Women with a BMI of 40 had a 6.25-fold increase in mortality rate (95\% CI 3.75-10.42). Data from the 2007-2008 NHANES report show that $68 \%$ the US population is overweight or obese [45]. In 2007, the Centers for Disease Control and Prevention found that $24.1 \%$ of the US population reported no leisure-time physical activity, and $48.8 \%$ were not meeting recommended levels of physical activity [46]. Given the current combination of high BMI and low activity among the population, endometrial cancer risk is an appreciable concern. Future studies need to consider how to increase physical activity in women at risk of developing endometrial cancer. Public health programs should be designed to promote exercise programs as an important intervention to minimize burden of both this disease and other weight-related health complications such as heart disease, diabetes, and hypertension. A randomized controlled trial on surrogate markers of risk or survival could be performed to further examine the relationship between endometrial cancer and physical activity, since to date all published studies on this relationship have been observational.

\section{Acknowledgments}

This study was supported by NCI-NIH grant 5R01CA098346. The cooperation of 28 Connecticut hospitals, including Charlotte Hungerford Hospital, Bridgeport Hospital, Danbury Hospital, Hartford Hospital, Middlesex 
Hospital, New Britain General Hospital, Bradley Memorial Hospital, Yale/New Haven Hospital, St. Francis Hospital and Medical Center, St. Mary's Hospital, Hospital of St. Raphael, St. Vincent's Medical Center, Stamford Hospital, William W. Backus Hospital, Windham Hospital, Eastern Connecticut Health Network, Griffin Hospital, Bristol Hospital, Johnson Memorial Hospital, Day Kimball Hospital, Greenwich Hospital, Lawrence and Memorial Hospital, Milford Hospital, New Milford Hospital, Norwalk Hospital, MidState Medical Center, John Dempsey Hospital and Waterbury Hospital, in allowing patient access, is gratefully acknowledged. This study was approved by the State of Connecticut Department of Public Health Human Investigation Committee. Certain data used in this study were obtained from the Connecticut Tumor Registry in the Connecticut Department of Public Health. The authors assume full responsibility for analyses and interpretation of these data. The authors want to specially thank Rajni Mehta for her support in case identification through RCA, Helen Sayward for her effort in conducting the study, Ellen Anderson, Donna Bowers, Renee Capasso, Kristin DeFrancesco, Anna Florczak, and Sherry Rowland for their assistance in recruiting and interviewing study participants, and $\mathrm{Na} \mathrm{Ni}$ for her help in SAS programming.

\section{References}

1. Endometrial Cancer. National Cancer Institute; Bethesda: 2010. (http://www.cancer.gov/cancertopics/types/endometrial)

2. Cancer Facts and Figures 2010. American Cancer Society; Atlanta: 2010. (http://www.cancer.org/Research/CancerFactsFigures/CancerFactsFigures/cancer-facts-andfigures-2010)

3. Paul T, John AB, Elisabete W, et al. Lifestyle and endometrial cancer risk: a cohort study from the Swedish twin registry. Int J Cancer. 1999; 82:38-42. [PubMed: 10360818]

4. Kaaks R, Lukanova A, Kurzer MS. Obesity, endogenous hormones, and endometrial cancer risk: a synthetic review. Cancer Epidemiol Biomarkers Prev. 2002; 11:1531-1543. [PubMed: 12496040]

5. McTiernan A. Mechanisms linking physical activity with cancer. Nat Rev Cancer. 2008; 8:205-211. [PubMed: 18235448]

6. Food, Nutrition, Physical Activity, and Prevention of Cancer: a Global Perspective. World Cancer Research Fund and American Institute for Cancer Research; 2007.

7. Voskuil DW, Monninkhof EM, Elias SG, et al. Physical activity and endometrial cancer risk, a systematic review of current evidence. Cancer Epidemiol Biomarkers Prev. 2007; 16:639-648. [PubMed: 17416752]

8. Cust AE, Armstrong BK, Friedenreich CM, et al. Physical activity and endometrial cancer risk: a review of the current evidence, biologic mechanisms and the quality of physical activity assessment methods. Cancer Causes Control. 2007; 18:243-258. [PubMed: 17206535]

9. Pukkala E, Poskiparta M, Apter D, et al. Life-long physical activity and cancer risk among Finnish female teachers. Eur J Cancer Prev. 1993; 2:369-376. [PubMed: 8401170]

10. Olson SH, Vena JE, Dorn JP, et al. Exercise, occupational activity, and risk of endometrial cancer. Ann Epidemiol. 1997; 7:46-53. [PubMed: 9034406]

11. Moradi T, Nyren O, Bergstrom R, et al. Risk for endometrial cancer in relation to occupational physical activity: a nationwide cohort study in Sweden. Int J Cancer. 1998; 76:665-670. [PubMed: 9610723]

12. Moradi T, Weiderpass E, Signorello LB, et al. Physical activity and postmenopausal endometrial cancer risk (Sweden). Cancer Causes Control. 2000; 11:829-837. [PubMed: 11075872]

13. Littman AJ, Voigt LF, Beresford SAA, et al. Recreational physical activity and endometrial cancer risk. Am J Epidemiol. 2001; 154:924-933. [PubMed: 11700247]

14. Furberg AS, Thune I. Metabolic abnormalities (hypertension, hyperglycemia and overweight), lifestyle (high energy intake and physical inactivity) and endometrial cancer risk in a Norwegian cohort. Int J Cancer. 2003; 104:669-676. [PubMed: 12640672]

15. Matthews $\mathrm{CE}, \mathrm{Xu} \mathrm{WH}$, Zheng W, et al. Physical activity and risk of endometrial cancer: a report from the Shanghai endometrial cancer study. Cancer Epidemiol Biomarkers Prev. 2005; 14:779785. [PubMed: 15824143]

16. Moore SC, Gierach GL, Schatzkin A, et al. Physical activity, sedentary behaviours, and the prevention of endometrial cancer. Br J Cancer. 2010; 103:933-938. [PubMed: 20877336]

17. Patel AV, Feigelson HS, Talbot JT, et al. The role of body weight in the relationship between physical activity and endometrial cancer: results from a large cohort of US women. Int J Cancer. 2008; 123:1877-1882. [PubMed: 18651569] 
18. Colbert LH, Lacey JV Jr, Schairer C, et al. Physical activity and risk of endometrial cancer in a prospective cohort study (United States). Cancer Causes Control. 2003; 14:559-567. [PubMed: 12948287]

19. Friedenreich C, Cust A, Lahmann PH, et al. Physical activity and risk of endometrial cancer: the European prospective investigation into cancer and nutrition. Int J Cancer. 2007; 121:347-355. [PubMed: 17357139]

20. Gierach GL, Chang SC, Brinton LA, et al. Physical activity, sedentary behavior, and endometrial cancer risk in the NIH-AARP Diet and Health Study. Int J Cancer. 2009; 124:2139-2147. [PubMed: 19123463]

21. Salazar-Martinez E, Lazcano-Ponce EC, Lira-Lira GG, et al. Case-control study of diabetes, obesity, physical activity and risk of endometrial cancer among Mexican women. Cancer Causes Control. 2000; 11:707-711. [PubMed: 11065007]

22. John EM, Koo J, Horn-Ross PL. Lifetime physical activity and risk of endometrial cancer. Cancer Epidemiol Biomarkers Prev. 2010; 19:1276-1283. [PubMed: 20406960]

23. Friberg E, Mantzoros CS, Wolk A. Physical activity and risk of endometrial cancer: a populationbased prospective cohort study. Cancer Epidemiol Biomarkers Prev. 2006; 15:2136-2140. [PubMed: 17057024]

24. Friedenreich C, Cook L, Magliocco A, et al. Case-control study of lifetime total physical activity and endometrial cancer risk. Cancer Causes Control. 21:1105-1116. [PubMed: 20336482]

25. Kriska A. Modifiable activity questionnaire. Medicine \& Science in Sports \& Exercise. A Collection of Physical Activity Questionnaires for Health-Related Researc. 1997; 29:73-78.

26. Haskell WL, Lee IM, Pate RR, et al. Physical activity and public health: updated recommendation for adults from the American College of Sports Medicine and the American Heart Association. Med Sci Sports Exerc. 2007; 39:1423-1434. [PubMed: 17762377]

27. Services HaH. Physical activity guidelines for Americans. Washington, DC: 2008.

28. Ainsworth BE, Haskell WL, Whitt MC, et al. Compendium of physical activities: an update of activity codes and MET intensities. Med Sci Sports Exerc. 2000; 32(9):S498-S516. [PubMed: 10993420]

29. Dosemeci M, Hayes RB, Vetter R, et al. Occupational physical activity, socioeconomic status, and risks of 15 cancer sites in Turkey. Cancer Causes Control. 1993; 4:313-321. [PubMed: 8347780]

30. Shu XO, Hatch MC, Zheng W, et al. Physical activity and risk of endometrial cancer. Epidemiology. 1993; 4:342-349. [PubMed: 8347745]

31. Conroy MB, Sattelmair JR, Cook NR, et al. Physical activity, adiposity, and risk of endometrial cancer. Cancer Causes Control. 2009; 20:1107-1115. [PubMed: 19247787]

32. Irwin ML, Mayer-Davis EJ, Addy CL, et al. Moderate-intensity physical activity and fasting insulin levels in women: the cross-cultural activity participation study. Diabetes Care. 2000; 23:449-454. [PubMed: 10857933]

33. Mayer-Davis EJ, D’ Agostino R Jr, Karter AJ, et al. Intensity and amount of physical activity in relation to insulin sensitivity: the insulin resistance atherosclerosis study. JAMA. 1998; 279:669674. [PubMed: 9496984]

34. Meijer EP, Goris AHC, Van Dongen JLJ, et al. Exercise-induced oxidative stress in older adults as a function of habitual activity level. J Am Geriatr Soc. 2002; 50:349-353. [PubMed: 12028219]

35. McTiernan A, Ulrich C, Slate S, et al. Physical activity and cancer etiology: associations and mechanisms. Cancer Causes Control. 1998; 9:487-509. [PubMed: 9934715]

36. Friedenreich CM, Orenstein MR. Physical activity and cancer prevention: etiologic evidence and biological mechanisms. J Nutr. 2002; 132:3456S-3464S. [PubMed: 12421870]

37. Katzmarzyk PT, Church TS, Craig CL, et al. Sitting time and mortality from all causes, cardiovascular disease, and cancer. Med Sci Sports Exerc. 2009; 41:998-1005. [PubMed: 19346988]

38. Hu FB, Li TY, Colditz GA, et al. Television watching and other sedentary behaviors in relation to risk of obesity and type 2 diabetes mellitus in women. JAMA. 2003; 289:1785-1791. [PubMed: 12684356] 
39. Dunstan D, Salmon J, Owen N, et al. Associations of TV viewing and physical activity with the metabolic syndrome in Australian adults. Diabetologia. 2005; 48:2254-2261. [PubMed: 16211373]

40. Ford ES, Kohl HW, Mokdad AH, et al. Sedentary behavior, physical activity, and the metabolic syndrome among US Adults[ast][ast]. Obesity. 2005; 13:608-614.

41. Lee IM. Physical activity and cancer prevention-data from epidemiologic studies. Med Sci Sports Exerc. 2003; 35:1823-1827. [PubMed: 14600545]

42. Shephard RJ. Limits to the measurement of habitual physical activity by questionnaires. $\mathrm{Br} \mathbf{J}$ Sports Med. 2003; 37:197-206. [PubMed: 12782543]

43. Amant F, Moerman P, Neven P, et al. Endometrial cancer. Lancet. 2005; 366:491-505. [PubMed: 16084259]

44. Calle EE, Rodriguez C, Walker-Thurmond K, et al. Overweight, obesity and mortality from cancer in a prospectively studied cohort of US adults. N Engl J Med. 2003; 348:1625-1638. [PubMed: 12711737]

45. Flegal KM, Carroll MD, Ogden CL, et al. Prevalence and trends in obesity among US adults, 1999-2008. JAMA. 2010; 303:235-241. [PubMed: 20071471]

46. US Physical activity statistics, centers for disease control and prevention, department of health and human services. 2010. (http://www.cdc.gov/nccdphp/dnpa/physical/stats/index.htm) 


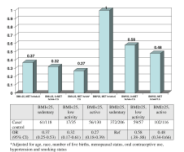

Fig. 1.

Composite measure of BMI and MV PA MET h/wk on endometrial cancer risk adjusted for age, race, number of live births, menopausal status, oral contraceptive use, hypertension, and smoking status 
Table 1

Description of the sample by case-control status

\begin{tabular}{|c|c|c|c|}
\hline & Cases $(n=667)$ & Controls $(n=662)$ & $\mathbf{P}^{a}$ \\
\hline \multicolumn{4}{|l|}{ Demographic and lifestyle factors } \\
\hline Age & $61.1(9.44)$ & $62.1(10.71)$ & $0.0526^{b}$ \\
\hline Race & & & 0.0096 \\
\hline White & $606(90.85)$ & $625(94.55)$ & \\
\hline Other & $61(9.15)$ & $36(5.45)$ & \\
\hline Education & & & 0.0003 \\
\hline 12 years or less & $237(35.53)$ & $174(26.32)$ & \\
\hline Greater than 12 years & $430(64.47)$ & 487 (73.68) & \\
\hline Body mass index $\left(\mathrm{kg} / \mathrm{m}^{2}\right)$ & $32.6(8.54)$ & $27.1(6.07)$ & $1.78 \times 10^{-38}$ \\
\hline Smoking status & & & 0.0187 \\
\hline Never smoker & $364(54.57)$ & $311(46.98)$ & \\
\hline Former smoker & $251(37.63)$ & $285(43.05)$ & \\
\hline Current smoker & $52(7.80)$ & $66(9.97)$ & \\
\hline Ever drank alcohol regularly & $307(46.23)$ & $400(60.51)$ & $3.79 \times 10^{-7}$ \\
\hline \multicolumn{4}{|l|}{ Reproductive factors } \\
\hline Number of live births & $1.8(1.36)$ & $2.1(1.32)$ & $4.42 \times 10^{-6}$ \\
\hline Ever gravid & $525(78.71)$ & $586(88.52)$ & $2.76 \times 10^{-6}$ \\
\hline Age at first pregnancy & $23.5(4.71)$ & $24.7(4.96)$ & $3.13 \times 10^{-5}$ \\
\hline Menopausal status & & & 0.031 \\
\hline Premenopausal & $91(13.66)$ & $119(17.98)$ & \\
\hline Postmenopausal & $575(86.34)$ & $543(82.02)$ & \\
\hline Oral contraceptive use (ever) & $374(56.33)$ & $440(66.67)$ & 0.0001 \\
\hline Menopausal hormone use (ever) & $198(30.23)$ & $239(37.52)$ & 0.0056 \\
\hline Menarche age & & & 0.047 \\
\hline$<12$ year & $186(28.10)$ & $153(23.32)$ & \\
\hline$\geq 12$ year & $476(71.90)$ & $503(76.68)$ & \\
\hline \multicolumn{4}{|l|}{ Medical history } \\
\hline Family history (yes/no $1^{\text {st }}$ degree relative with endometrial cancer) & $46(6.90)$ & $27(4.08)$ & 0.024 \\
\hline MD diagnosis of hypertension (ever) & $378(56.67)$ & $257(38.82)$ & $1.43 \times 10^{-10}$ \\
\hline MD diagnosis of diabetes (ever) & $136(20.39)$ & $77(11.63)$ & $2.70 \times 10^{-5}$ \\
\hline
\end{tabular}




\section{Table 2}

Moderate to vigorous-intensity sports/recreational physical activity level by case-control status

\begin{tabular}{llcl}
\hline Characteristic & Cases $(\boldsymbol{n}=\mathbf{6 6 7})$ & Controls $(\boldsymbol{n}=\mathbf{6 6 2})$ & $\mathbf{P}^{\boldsymbol{a}}$ \\
\hline Total sitting time (h/day) & $6.44(2.97)$ & $5.54(2.85)$ & $3.82 \times 10^{-9}$ \\
MV PA MET h/wk in 2-5 years before interview & $5.20(10.23)$ & $8.31(12.80)$ & $3.19 \times 10^{-9}$ \\
MV PA MET h/wk from age 30-40 & $8.74(17.31)$ & $11.53(22.63)$ & 0.022 \\
\hline
\end{tabular}

Table values are mean (SD)

${ }^{a} p$-value is for $t$-test 


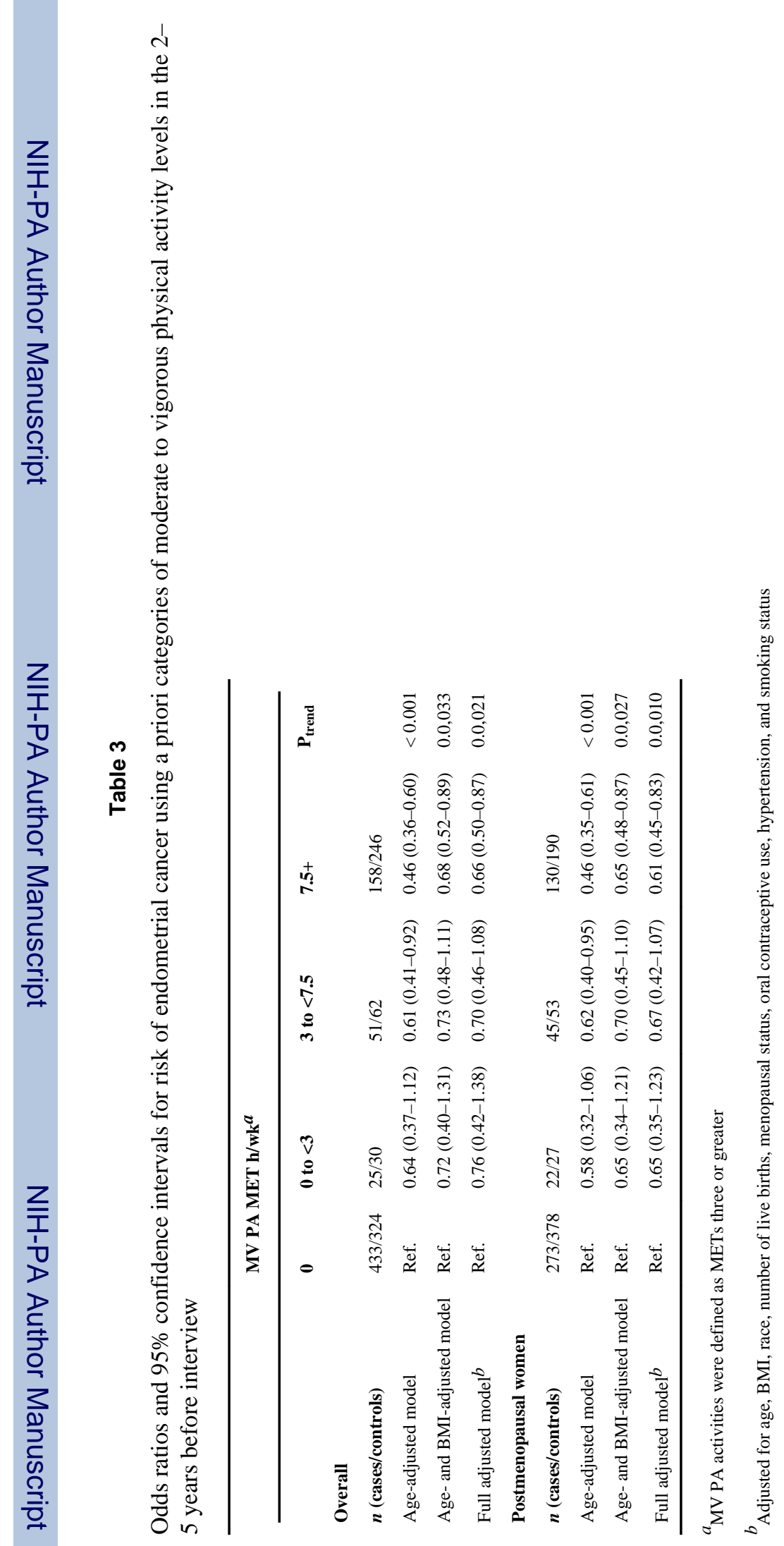




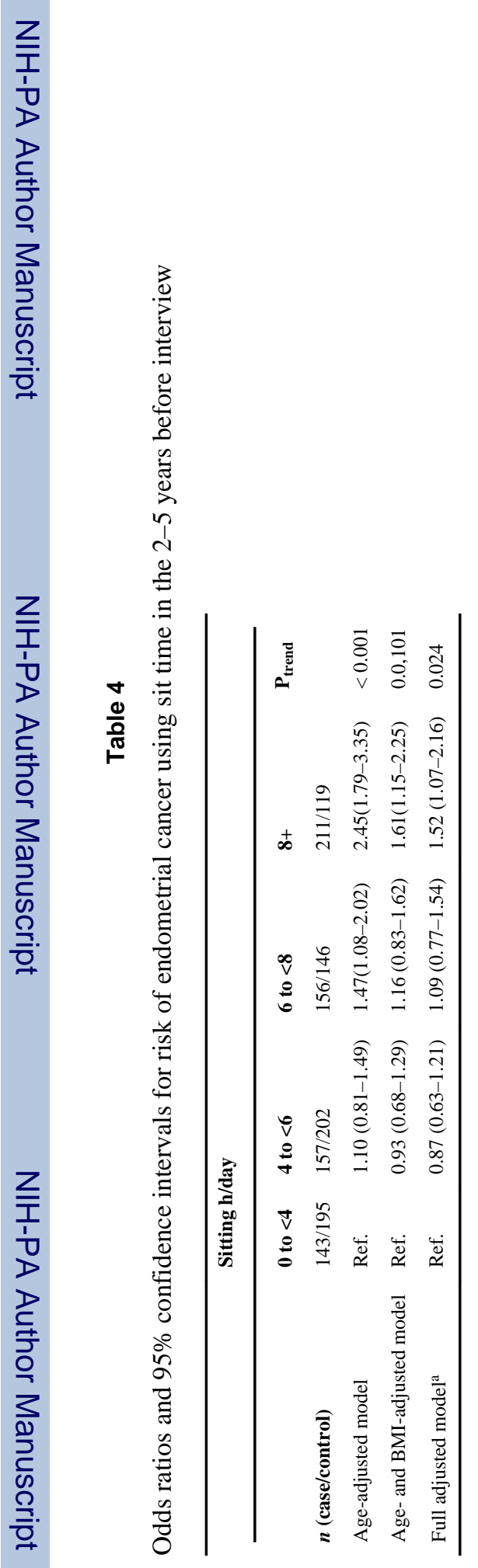

